\title{
Plan for sustainable urban logistics - comparing between Scandinavian and UK practices
}

\author{
Karin Fossheim $^{1}$ - Jardar Andersen ${ }^{1}$
}

Received: 23 December 2016/Accepted: 9 October 2017 / Published online: 18 October 2017

(C) The Author(s) 2017. This article is an open access publication

\begin{abstract}
Introduction Common practices in current urban logistics planning in Scandinavia and the UK, and the degree to which SUTP (Sustainable Urban Transport Plan), SUMP (Sustainable Urban Mobility Plans) and SULP (Sustainable Urban Logistics Plans) guidelines are used, are examined in this paper.

Methods A systematic literature review identifies relevant studies based on predefined inclusion criteria: mobility, freight, urban, plan.

Results It is found that urban freight plans are used more frequently in the UK than in the Scandinavian countries. SULPs (freight strategies, action plans or parts of a mobility plan) follow a structure that identifies the current situation and defines the strategic context, vision, targets and objectives using selected policy measures, measures that are dependent on geographical scope.

Conclusions Urban freight plans are designed with a sustainability perspective to define visions and policy measures for urban freight. SUTP, SUMP and SULP methodologies are used in existing Scandinavian and UK urban freight plans, especially when a collaborative planning approach is being practiced. The emphasis on urban freight is challenged by the regional perspective. Integrating urban freight in general planning procedures or transport planning is important. Government guidance and sustainable strategies can provide
\end{abstract}

This article is part of Topical Collection on Accommodating urban freight in city planning

Karin Fossheim

kfo@toi.no

Institute of Transport Economics, Gaustadalléen 21, 0349 Oslo, Norway a planning methodology and, therefore, based on national guidelines further European structural standardisation could be beneficial. Identification of freight plans is crucial if the contributions they make are to be determined.

Keywords Urban freight $\cdot$ Freight plans $\cdot$ Urban development $\cdot$ City planning $\cdot$ SULP

\section{Introduction}

Urban areas present national and international freight transport with a challenge in terms of both logistical performance and environmental impact. Goods, waste and service trips in urban areas have negative traffic and environmental impacts and take place in space shared with many other actors, including public transport operators, private car users, taxis, cyclists and pedestrians. The European Commission [1] has pointed out several of the key challenges of urban logistics:

1. A lack of focus and strategy on urban logistics, and only a few cities with someone in authority responsible for urban logistics.

2. A lack of coordination among actors involved in urban logistics, and in many cases insufficient dialogue between city authorities and the private actors who operate there.

3. A lack of data and information, which makes it difficult to improve operational efficiency and long-term planning.

Within transport planning and sustainable cities, the focus has traditionally been on public transport and car-use, with little attention given to freight transport issues [2]. To improve urban freight planning, the European Commission [3] has emphasised that urban logistics planning should be one of 
the components of a Sustainable Urban Mobility Plan (SUMP), one goal of which is to improve the accessibility of urban areas and provide high-quality, sustainable mobility and freight transport to, through and within the urban area [3]. Additionally, the EU has stated that urban freight plans should present measures to deal with the efficiency of urban logistics, including urban freight delivery, while also reducing the related externalities of greenhouse gas emissions and noise. Thus, the concept of a Sustainable Urban Logistics Plan (SULP) was launched to cover the logistics component of a SUMP [4]. Following this increased attention to SULPs in cities and the growing number of research initiatives, there is a need to identify the current state-of-the-practice of SULPs and freightrelated SUMPs.

Because urban freight is considered a private complex matter, a lack of planning methodology and various stakeholders and re-election constraints, policy-making is viewed as a challenge to local bureaucrats $[5,6]$. Today, public planning procedures rarely include the perspectives of all private sector stakeholders (such as logistics operators and other types of business), rendering policies relatively uncoordinated and inefficient $[7,8]$. Thus, a more systematic approach, e.g. SULP, is needed locally to improve the situation and cope with the challenges now facing many cities [6]. In contributing to this, the purpose of our paper is to compare, first, between Scandinavia and the UK to identify common urban freight planning practices in current urban freight plans and, second, the degree to which the SUTP, SUMP, SULP guidelines are used in urban freight plans. Structured comparison of existing freight plans might provide an increased common understanding of the operationalisation of the SULP concept, thus ensuring further development in the same direction. In addition, identifying current urban freight planning practices can contribute to efficient planning and management of urban freight in making cities more attractive $[9,10]$.

Very few reviews of urban freight planning have been identified [7]. Those that exist focus on stakeholder perceptions rather than plan content or they assess freight plans in one, or only a few, cities rather than with the comparative Scandinavian and UK perspective which this review aims to provide $[6,11-13]$. The work was undertaken as part of a national research project (NORSULP Sustainable Urban Logistics Plans in Norway) aiming to help the largest cities in Norway develop sustainable urban logistics plans. NORSULP will contribute to improved mobility for all users of urban transport infrastructure and urban mobility systems [14].

The remainder of this study is structured as follows. Existing European guidelines for urban freight planning are described in Section 2, the research methodology in Section 3, and the results in section 4. Finally, based on the review, common features are discussed in section 5 , with the main findings concluded in section 6 .

\section{Existing European guidelines for urban freight planning}

Despite local authorities being the decision-making bodies on urban freight policies, regulations and plans, European guidelines aim at a theoretical planning methodology or policy support document on how urban freight measures should be developed and implemented [6]. These are often a result of European projects within urban mobility, e.g. ENCLOSE $[15,16]$. The main ones are: (i) Sustainable Urban Transport Plans (SUTP) [17, 18], (ii) Sustainable Urban Mobility Plans (SUMP) [19] and, (iii) Sustainable Urban Logistics Plans (SULP) [4].

The Sustainable Urban Transport Plan (SUTP) developed and tested in the projects BUSTRIP and PILOT is 'an integrated approach with the goal of overcoming deficits in the coordination and cooperation across administrative borders, as well as between authorities in national hierarchies'. These plans seek to develop a comprehensive method targeting all transport modes in urban areas [20]. When designing SUTPs, the planning principle behind ensuring policy implementation is a longterm urban freight transport strategy embedded in an overall sustainable development strategy. In addition, the plans should have a regional scope and be developed through stakeholder consultation if they are to secure acceptance and legitimacy. Finally, actor cooperation and policy coordination can ensure integration between transport modes, and capacity building can ensure the necessary skills $[2,6,11,20,21]$. Running the SUTP process can be split into five tasks before being adopted:

- Status analysis and scenario development

- Vision, objectives and targets

- Action and budget plan

- Assessment of responsibilities and resources

- Monitoring and evaluation [18].

A SUMP is a 'strategic plan designed to satisfy the mobility needs of people and businesses in cities and their surroundings for a better quality of life. It builds on existing planning practices and takes due consideration of integration, participation, and evaluation principles' [19, 22]. As mentioned, the extent to which freight has been emphasised or even included in these guidelines varies greatly, in particular urban freight. However, the methodology and the experiences gained through developing such plans can be important in urban freight planning. There may be potential for transfer from EU projects (see, for example, ADVANCE, PolySUMP, SUMPs-Up, ENDURANCE and FormelM ${ }^{1}$ ), which develop guidelines, tools and handbooks on how participating cities can develop SUMPs. Of the 11 steps leading to

\footnotetext{
${ }^{1}$ These are just a selection of SUMP-related EU projects. For more projects on this topic, visit http://www.eltis.org/mobility-plans.
} 
development of a SUMP, the following is a summary of those that, potentially, could be transferred to urban freight plans:

- Defining the potential, development process and scope of the plan

- Analysing the mobility situation, developing scenarios and visions

- Setting priorities/targets and developing effective packages of measures

- Clarifying responsibilities, allocating budgets and building into the plan systems for monitoring and assessment [19].

In addition, the Poly-SUMP methodology advises on matters for polycentric cities arising from SUMP methodology: (i) prepare well by understanding your region; (ii) create common ground and vision; and (iii) use the outcomes and elaborate the plan [23]. This indicates a common understanding of SUMP methodology.

The final category of theoretical guidelines, SULP, is a holistic planning strategy for urban freight that ensures efficient and sustainable logistics operations within urban areas [14]. The IEE initiative ENCLOSE has contributed to the development of SULPs in a number of small and mid-sized European towns in pursuing the same logic as the SUMP initiatives and in including the following tasks that have to be carried out by each town $[12,15]$ :

- Analysis of the logistics baseline and scenario development

- Setting the vision, objective and targets/priorities

- Identification of policy measures impacts and service design - organisation, business model and contracting

- Assignment of responsibilities and arranging for implementation of a roadmap and monitoring plan.

\section{Methodology}

This systematic review answers a specific question using predefined criteria capturing all relevant plans and studies [24, 25]. The search strategy reviewing urban freight plans was defined a priori with the goal 'of reducing bias by identifying, appraising, and synthesising all relevant literature on this topic' [26]. In ensuring this, the predefined inclusion criteria are grouped into four main categories: mobility, freight, urban and plan, and to capture mobility the keywords 'transport', 'mobility' and 'travel' are used. The freight category is made up of five keywords: 'logistics', 'delivery', 'freight', 'carriage' and 'distribution'. Urban consists of 'urban', 'city', 'central', 'metropolitan', 'inner-city', 'town', 'region' and 'county', while plan includes 'action', 'programme', 'project', 'method', 'suggestion', 'procedure', 'plan' and 'strategy'. In sum, different combinations of the 21 keywords were used to identify current urban freight plans. These concepts were selected thematically based on the research question and on the definitions of SUTP, SUMP and SULP. Identifying the concepts from the research question pinpointed available data, guided the collected data and limited subjective assessments, thus providing a structured and critical evaluation of validity and reliability [24]. The government documents, books, scientific journal articles, websites and plans analysed include all (at least three) of the concepts identifying existing experiences and comparing between Scandinavian and UK SULP initiatives. The methodology is described in the figure below (Fig. 1).

Since this review is concerned with the current practice in urban logistics plans, the selected criteria systematically limit the conceptual framework and scope of the study [24]. The search to identify city plans, public documents and reports was completed between January and September 2016 and actioned through the Google Scholar and Google search engines. The scope of the article is limited to Scandinavia and the UK, where several urban freight plans are identified. It is valuable to compare Scandinavia with UK since they are organised similarly but UK is considered relatively more advanced when it comes to urban freight initiatives [27]. Comparisons are made across the Scandinavian countries, which share a common history and have developed relatively similar political, economic and social systems [28]. The review separates between: (i) regional and (ii) local and city level urban freight plans. The regional level are freight plans, which among other freight transport issues, includes sections on urban freight. These plans are implemented and/or developed in a county, metropolitan area or region. Local and city level freight plans focus explicitly on urban freight issues and are implemented and/or developed by a municipality or local district i.e. borough or city. ${ }^{2}$ Logistics, or city/urban logistics, is seen as the system or strategy ensuring efficient urban freight movements, while urban freight is the transportation of goods in an urban area. The review focuses on goods distribution in an urban area or region compared to a rural area; hence the concept 'freight' is applied [29, 30].

\section{Existing regional, local and city freight plans in Scandinavia and UK}

Existing freight and logistics plans are discussed in this section: the planning types used in urban freight in the first subsection; the organisational structure in relation to the European guidelines in the second; the policy measures suggested in each identified plan in the third; and the sustainability focus of the plans in the final subsection. Regions or cities identified with plans are listed in Table 1.

\footnotetext{
${ }^{2}$ The London Freight Plan is the exception since it focuses on urban freight issues but implemented within a metropolitan area.
} 
Fig. 1 Inclusion criteria of selected urban-freight-related documents

\section{Systematic review}

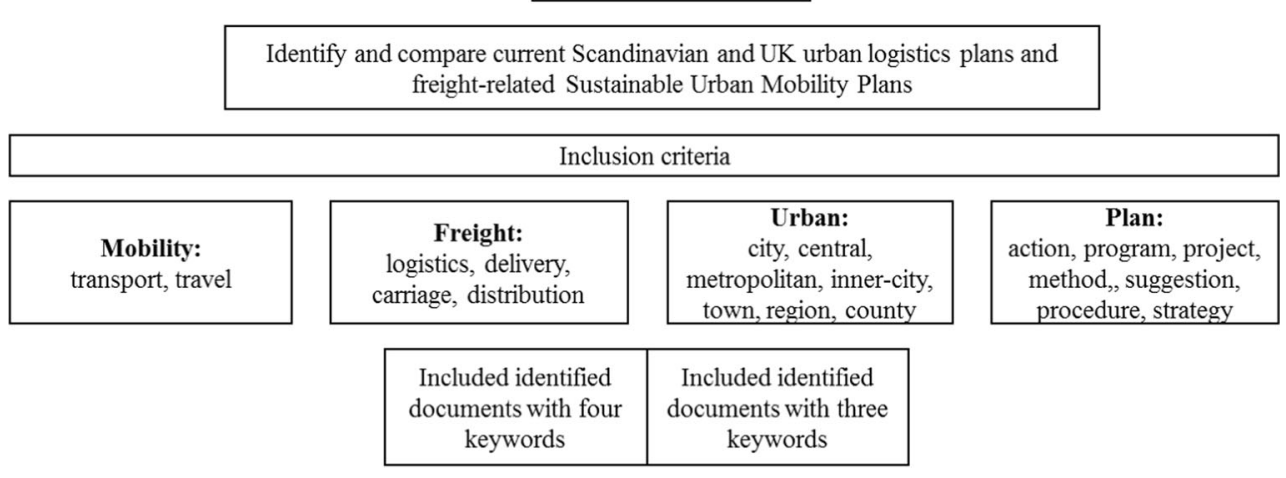

\subsection{Urban freight strategies and action plans}

With links to different planning contexts, the locally defined freight strategy of most identified urban freight plans is combined with a detailed freight measure action plan. See Table 2 for an overview of the type of planning document, plan additions and their contextual framework.

In most cases, the existing UK freight plans are supporting elements of an overall Local Transport Plan (LTP), often as freight strategies that sometimes include a freight action plan [45, 46, 48, 51], e.g. the strategic plan for transport in Kent can be found in Kent's third Local Transport Plan [37]. The Local Transport Plan is the local authorities' key freight guiding policy document; it incorporates freight issues in the wider transport context of other transport strategies [35, 53]. For example, in Somerset it sets out how to improve the way freight is moved around the region [36]. Aberdeen [47], on the other hand, has developed a SUMP which is essentially a transport masterplan examining the way people move around by different modes of transport together with the Aberdeen City Local Transport Strategy [48, 49]. Like Aberdeen the Scandinavian freight plans are organised differently as there is no requirement of a LTP including urban freight. In Danish cities the use of physical and road network planning have been emphasised when regulating and planning for urban freight [42]. The Stockholm Freight Plan, which summarises freight-deliveryrelated goals and presents concrete actions, is organised as part of the city's 'Urban Mobility Strategy' [16, 54]. Similarly, in Malmö the freight programme is part of Malmö's new 'Traffic and Mobility plan' [55]. However, without the presence of an LTP, and similar to the British cases, the Swedish freight plans have developed or will develop action plans [16, 32, 44]. In some, the strategic plan for goods traffic is combined with the action plan, which specifies measures rather than itself being specified as a separate document [56].

Regarding legal status of the freight plans the UK LTP is a long-term statutory transport policy framework document setting out future development of the area through stakeholder consultation in the planning process $[57] .^{3}$ The Freight Strategies and the supporting documents on the other hand are non-statutory, which means that the plan does not have to be adopted by the Council Members [27]. However, freight plans have been developed to implement the LTP, which is itself a statutory document [41]. In the Scandinavian cases, the legal status of the planning document is varying; however, the Västra Götaland Freight Strategy has been implemented by the regional board in Västra Götaland [31] and in Malmö the plans have been politically adopted by the City Council $[44,55,58]$.

The UK LTPs, their supporting freight strategies and detailed freight action plans, are developed based on national government guidelines and recommendations intended to advise and inform design and development. The national guidance provides good UK practice on urban freight plans [59], and they set out goals for transport planning in a defined planning period, thus providing ideas about measures and visions adjusted to fit each local context. Merseyside applies the following from Department for Transport national freight policies: 'Guidance on Local Transport Plans' [60], 'Delivering a Sustainable Transport System: the Logistics Perspective' [61] and 'White Paper - Creating Growth, Cutting Carbon' [39, $62] .{ }^{4}$ The national guidelines related to urban freight in Sweden, do not, as in the UK, mainly focus on urban freight but has a more overall urban mobility perspective. In Västra Götaland the following documents are important: Vision Västra Götaland 2020, Climate Strategy Västra Götaland, EU 2011 White Paper on Transport, Gothenburg 2035 Near Metropolitan Traffic Strategy and Västra Götaland Maritime Strategy [31]. Combining national guideline documents and the creation of a Sustainable Urban Mobility Strategy is another approach [44]. In Stockholm, the freight strategy has been developed from a City of Stockholm initiative within

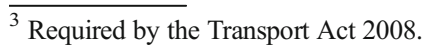

${ }^{4}$ Other documents are, for example, 'Scottish Government Transportation Noise Action Plan' [63] and 'National Planning Policy Framework' [64],

'Tactran Regional Transport Strategy' [65] and 'Local Development Management Strategy’ [66].
} 
Table 1 Urban freight plans categorised by geographical level

\begin{tabular}{|c|c|c|c|c|}
\hline & \multicolumn{3}{|l|}{ Scandinavia } & \multirow[t]{2}{*}{ United Kingdom $^{\mathrm{a}}$} \\
\hline & Denmark & Norway & Sweden & \\
\hline Regional level & & & Västra Götaland [31, 32] & $\begin{array}{l}\text { Northamptonshire [33] } \\
\text { Surrey [34] } \\
\text { Staffordshire [35] } \\
\text { Somerset [36] } \\
\text { Kent [37] } \\
\text { West Midlands [38] } \\
\text { Merseyside [39] } \\
\text { South Hampshire [40] } \\
\text { London [41] }\end{array}$ \\
\hline Local and city level & $\begin{array}{l}\text { Aalborg } \\
\text { Århus } \\
\text { Odense } \\
\text { Copenhagen } \\
\text { Kolding [42] }\end{array}$ & Bergen [43] & $\begin{array}{l}\text { Malmö [44] } \\
\text { Stockholm [16] }\end{array}$ & $\begin{array}{l}\text { Bedford [45] } \\
\text { West Berkshire [46] }^{\text {Aberdeen }}{ }^{\mathrm{b}}[47-50] \\
\text { Dundee [51] }\end{array}$ \\
\hline
\end{tabular}

${ }^{\text {a }}$ England and Scotland are listed together since they have similar basic planning structures. However, it is worth noting that there are some differences in how each planning system works [52].

${ }^{\mathrm{b}}$ Even tough Aberdeen has plans on both levels the most recent work are undertaken at the local level by the Aberdeen City Council [47-49].

the context of the City Plan, which is a SUMP that includes freight as one of seven mobility topics [16]. On a general level, Scandinavian planning guidance is more ad hoc based on national forums and public-private partnerships.

\subsection{Urban freight plan contents framework}

Overall, most freight strategies identified have a vision and status (of urban freight within a given geographical area) specified by several objectives followed by measures targeting these objectives, while the action plan provides detailed links between the selected measures and the identified objectives in each area [37]. Most of the visions or aims of the identified urban freight plans focus on the need for sustainable freight distribution in the area in terms of economic efficiency/ growth, environmental protection and social equity, e.g. 'To facilitate the safe and efficient transportation of freight into, out of and within the TFSH sub-region, supporting a competitive local and regional economy, whilst taking into account the existing and future needs of our society and the environment' [40]. The exceptions to this sustainability focus are Stockholm, which highlights an efficient freight system in a viable city, and Dundee, which focuses on environmental protection [16, 51]. The challenges expected when coming up against these objectives are then set out, along with a number of measures for resolving them followed by an action plan for implementation of the preferred strategy [36].

Looking at the European guidelines, urban freight plans apply essential components of the SUTP, SUMP and the further developed SULP methodology. Recommendations about including the current situation, strategic context, vision, targets, key objectives and policy measures are followed in both regional and local/city level plans. For example, in Västra Götaland the following five elements are main headlines in the freight strategy:

- Freight strategy vision, objectives and targets

- Current situation of urban freight in Västra Götaland

- Freight trends and forecasts

- Regional challenges

- $\quad$ Strategic areas [31].

Some of the planning steps in the SUMP methodology can be identified in the Stockholm Urban Mobility Strategy [54], too, e.g. overall strategy defining the potential, objectives setting visions and aims targeted by effective packages of measures.

\subsection{Planned urban freight policy measures}

All the plans identified define one or more policy measure needed to improve a situation. The selection of measures depends on the freight-related issues faced in each region, the political agenda, environmental ambitions, interest groups and evaluation/achievements of previous transport plans [67]. Tables 3 and 4, applying the NCFRP Report 33 "Improving Freight System Performance in Metropolitan Areas: A Planning Guide", 2015 [68] and categorisation of urban 


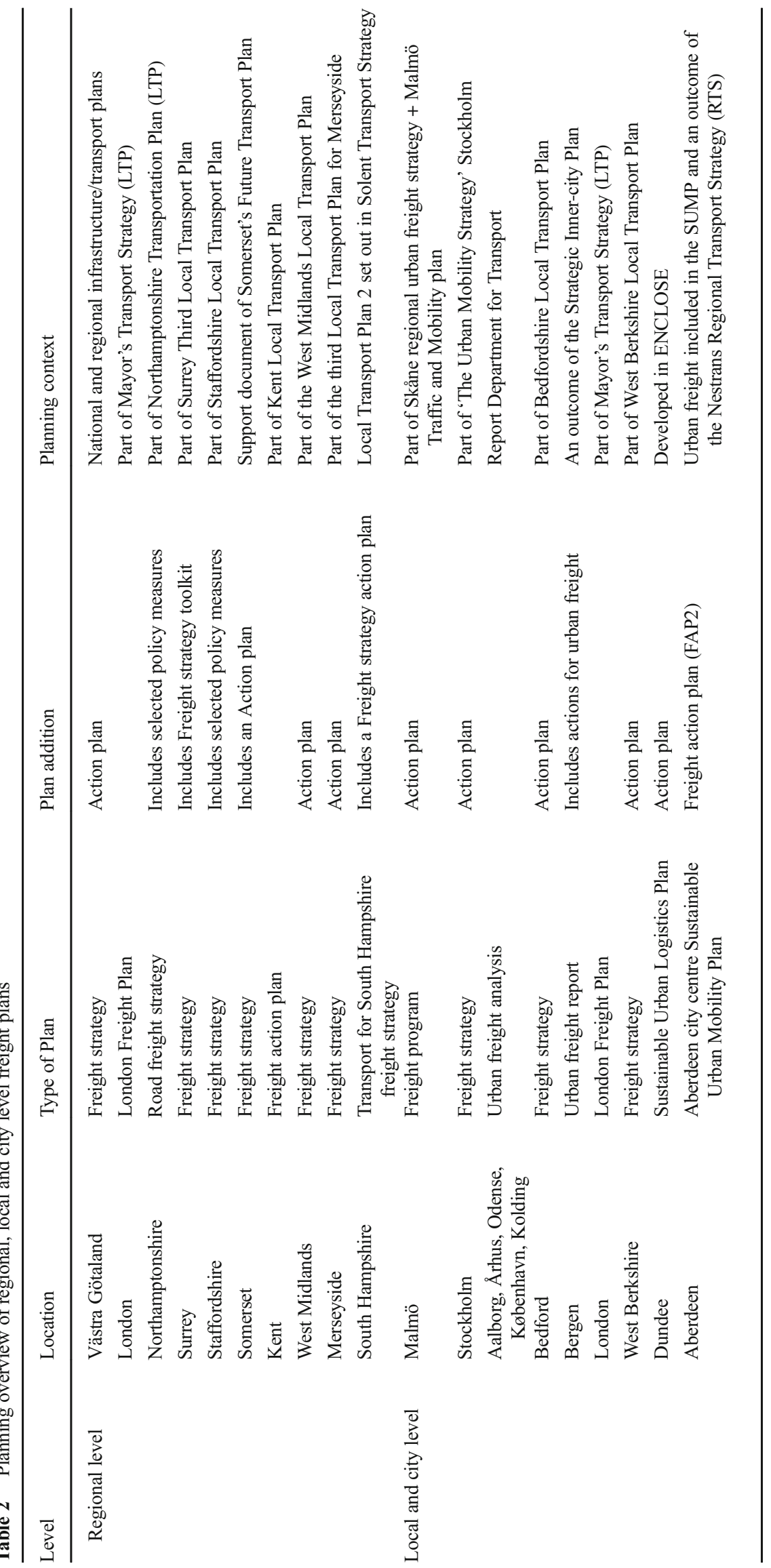




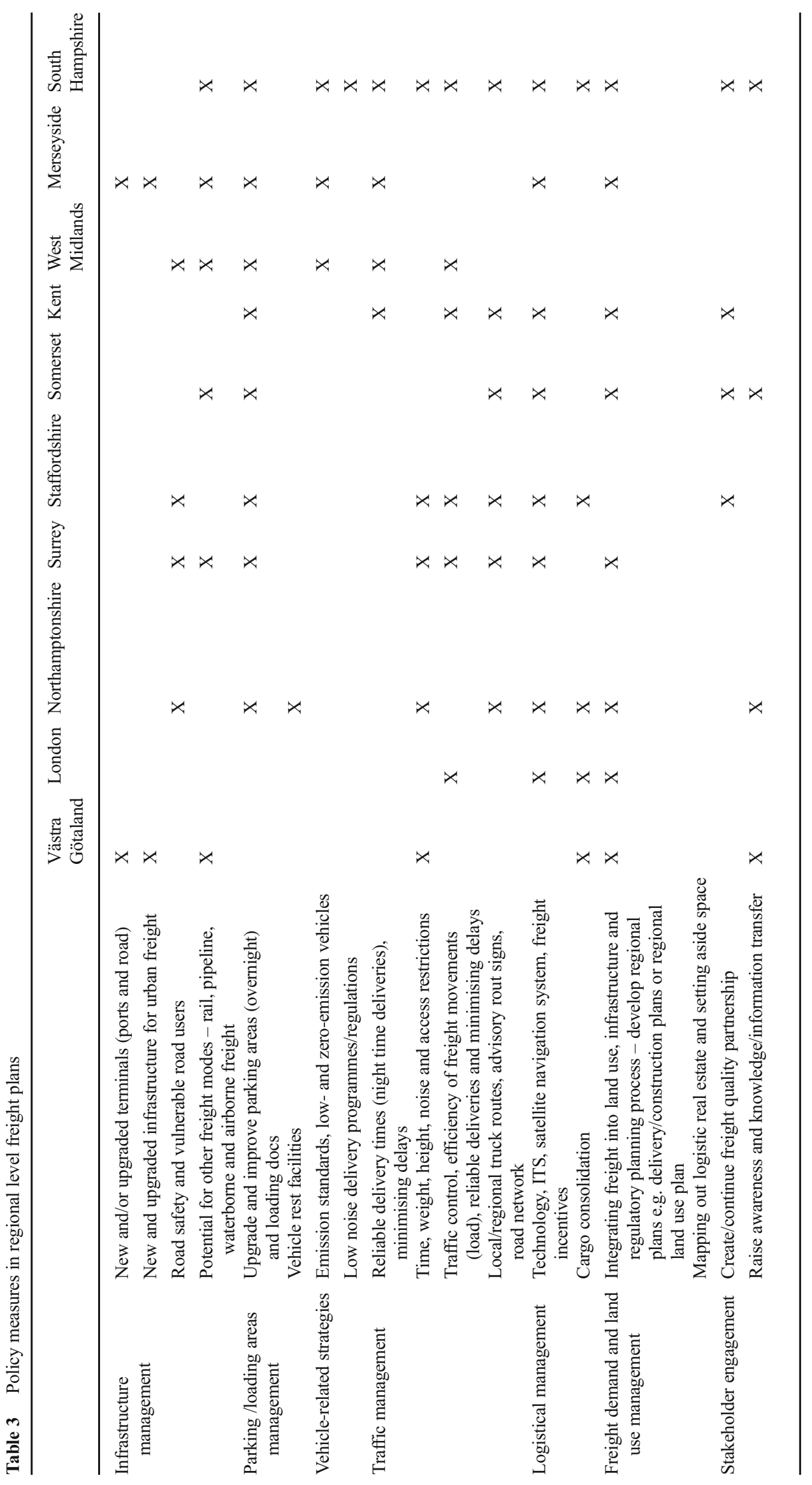




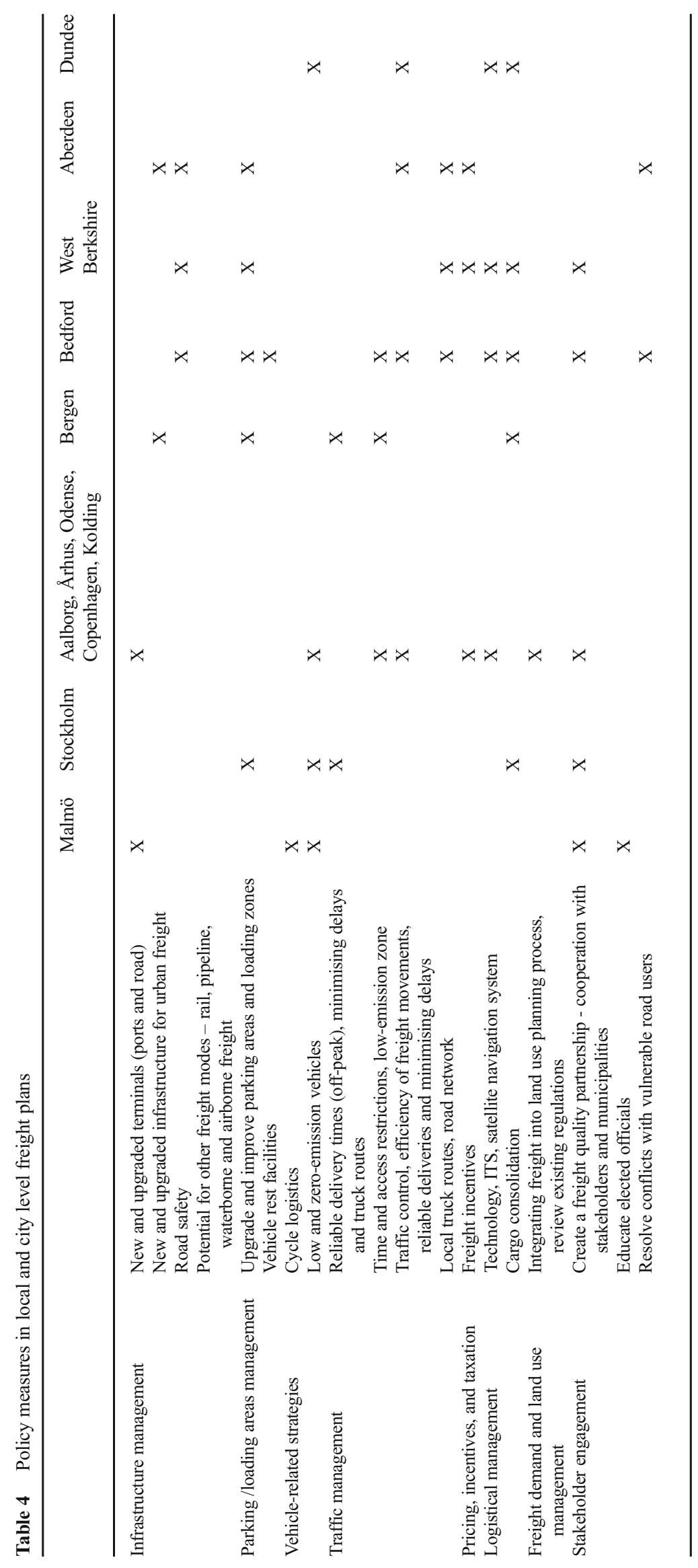


freight measures, identify the highlighted policy measures in regional and local and city level urban freight plans, respectively.

One way of distinguishing between freight measures, as in Surrey, is to separate between countywide freight measures, building on existing initiatives and local freight measures that address specific freight issues [34]. The identified freight strategies covering a regional geographical area, such as Surrey, Staffordshire or Västra Götaland, focus less on urban freight and more on regional overarching transport measures. The selected policy measures in regional freight plans are to a greater degree targeted at long-haul transport, aviation, sea and rail transport in the region [40]. Local and city level plans, such as in Malmö, Bedford and Dundee, focus on urban transport measures and a limited number of regional measures.

These differences are evident when comparing the strategies of Stockholm and Staffordshire. Stockholm focuses on low and zero-emission vehicles, off-peak delivery times, cargo consolidation and Freight Quality Partnership, whereas Staffordshire, for example, highlights truck routes, satellite navigation, ITS, infrastructure and the regulatory planning process, and potential for other freight modes. Hence, the plan has a greater long-haul transport perspective across municipal borders.

Overall, the following policy measures are those most often listed in regional-level freight plans:

- $\quad$ Parking and loading area management

- Technology, ITS, satellite navigation systems

- Integration of freight in infrastructure planning and in the regulatory planning process by developing regional plans, e.g. delivery/construction plans or regional land-use plans.

Among the freight plans identified in a local geographical area, the most often mentioned freight policy measures are:

- Creation of a freight quality partnership and cooperation with stakeholders and other municipalities

- Traffic control, efficiency of freight movements, reliable deliveries and minimising delays.

\subsection{Sustainability in urban freight plans}

Sustainability is a key element of European and national urban mobility and logistics strategies, and, along with sustainable development, is defined according to the Brundtland Report [69] by the three components: economic growth, environmental protection to meet the needs of future generations and social equity to accommodate future generations [70]. The urban freight plans identified ensure the sustainability aspect by viewing freight together with its surrounding environment. Altogether, the identified freight plans safeguard all three sustainability components; however, environmental impact can be identified as the main driver comparing across countries. Only two plans, those of Dundee and London, are labelled as Sustainable Urban Logistics Plans or plans for sustainable urban freight transport $[41,51]$.

The sustainability focus is more comprehensive and structured, including all three components, in the UK freight plans identified compared to the Scandinavian plans. Whether the economic, environmental or social impact of freight transport is emphasised differs to some extent in each city. For example, in Västra Götaland, social equity is less prioritised, while Malmö has less focus on economic growth/efficiency and in Stockholm the focus is mostly on environmental protection $[16,31,55]$. These differences within Sweden probably have to do with the type of plan each municipality apply i.e. as part of the Local Transport plan or as a locally developed mobility/ city plan, and also with the availability of national guidance focusing on sustainability. In the UK cases, the Department for Transport national guidance ${ }^{5}$ stipulates guiding urban freight goals and therefore a methodology used to develop the sustainable urban freight plans, thus capturing the contribution to our economic growth together with environmental and social costs [36]. The goals for transport planning are:

1) To support economic growth

2) To reduce carbon emissions

3) To promote equality of opportunity

4) To contribute to better safety, security and health

5) To improve quality of life and a healthy natural environment [71]

\section{Common current urban freight plan practices in Scandinavia and the UK}

This section discusses common features of the urban freight plans and implications of the existing practices presented as results above. Overall, our findings suggest that a sustainable urban freight plan is a political process of providing guidance and facilitating freight-related activities, thus making economic, social and environmental decisions affecting freight in urban areas. The content of these plans includes information on urban freight status and background, urban freight challenges and policy solutions allowing local authorities and other stakeholders to manage urban freight activities [56].

Planning for sustainable development of urban freight transport is, with some national differences, done through the combination of an economically, environmentally and

\footnotetext{
5 'Delivering a Sustainable Transport System' ('DaSTS') [71] taken up by the 'Guidance on Local Transport Plans' [60] and 'DaSTS: the Logistics Perspective’ [61].
} 
socially focused freight strategy with a detailed freight action plan. The strategic plan contains overreaching strategic or general guidelines where urban freight objectives for the area are identified. These strategies are complemented by urban freight policy measures for the urban area. In most cases the strategy and plan constitute two separate documents; however, combining them into one document could provide a more detailed thematic overview. All in all, freight-related issues must be emphasised in overall local, regional and national planning strategies integrating freight in general urban planning either as a Local Transport plan or as part of a mobility/ city plan [70].

\subsection{Stakeholder consultation in urban freight planning}

In line with the Browne et al. [72] comparison of Paris and London, targeted stakeholder consultation communicating knowledge on freight issues and priorities for action, as well as involvement in the planning process, are practised in the freight plans identified in this paper. This complies with the emphasis on stakeholder consultation as key in urban freight planning $[2,10,73,74]$. Collaboration is also highlighted as a key element in the SUTP, SUMP and SULP methodology fundamental to improvement of the planning procedures [74]. Key stakeholders involved in the identified planning process are: logistics service providers, suppliers, receivers, parish councils, road haulage operators and delivery companies, and heavy goods vehicle drivers [2]. In Västra Götaland, for example, a freight strategy reference group with representatives from municipalities, municipal associations, businesses, academia, research institutes, NGOs and government agencies is involved in the planning [31]. Freight plans are designed to best serve the needs of both the freight industry and local communities by consulting with local authorities, representatives of the freight and logistics community. The use of a collaborative approach is in line with Lindholm's [20] conclusion that including all relevant stakeholders in the planning process secures acceptance, thus increasing the likelihood of the plan delivering its full potential benefit [39].

\subsection{Geographically integrated transport planning}

May et al. [75] argue the importance of integrated transport planning. In practice, Scandinavian and UK urban freight plans are all incorporated in an executive urban plan - either a local transport plan or an urban mobility plan - along with urban strategies such as congestion, biking, road safety, air quality and parking $[34,54]$.

Another aspect of transport planning is the idea of local, regional and national geographical planning integration. The challenge of retaining an urban focus while accounting for regional flows and national freight networks, as questioned in Cui et al. [10], is confirmed in this study. To integrate a regional perspective, the local and city level plans include a limited number of rural measures providing insights to the overall transport picture [6]. The references to national recommendations and the existence of regional freight plans with an urban logistics component indicate that this is considered important in urban freight planning. However, the findings suggest that planning with a regional focus reduces the urban perspective to some extent. Focusing too much on a regional perspective in urban freight plans seems to shift the emphasis from urban issues to heavy goods vehicles and long haul transport, resulting in different policy measures $[10,76]$. Furthermore, there are more listed policies in freight plans with the regional perspective, potentially due to a broader spectre of freight issues being included [40]. Also, SUTP methodology [7] emphasises that transport plans should have a regional scope; however, this paper suggests that for urban freight a local or city perspective is recommended to maintain proper emphasis on the urban challenges and solutions.

\subsection{Responding to government guidance - national recommendations, sustainability strategies and European guidelines}

A common finding is that there would be increased up-take of urban freight plans if some guidance were given by the central government. With no national requirements, one way of guiding freight strategy development is by including it in the region or city's sustainable urban mobility plan or climate and energy strategy $[6,11]$. Using sustainability strategies to support urban freight plans proves the importance of integrated planning procedures. It is a way to include urban freight in overall transport planning, as discussed by Lindholm and Behrends [6]. As is evident from the variations on structure and content in Swedish plans compared to UK plans, limited national guidance can result in differences on whether focus should be on detailed policy measures or on more general objectives and targets. These findings suggest that statutory local transport plans and national logistics guidelines developed to support the planning process might be a prerequisite to increasing the development of such plans [71]. In summary, there might be a need for executive recommendations to emphasise urban freight in local planning. Hence, national government has an important role through its investment, regulation, overall policy strategies and planning framework in highlighting freight [30].

Most of the existing plans identified have applied elements of the guidance provided by the European SUTP, SUMP and SULP methodologies; in particular, the methodology on how to structure the plan and the inclusion of all relevant stakeholders in the planning process used [22]. This attempt to methodologically standardise a freight plan can generate cross-national transfer of knowledge and experience within this area. 


\subsection{Collective lack of urban freight plan evaluation}

'Overall, this strategy was successful, and targets [...] met' [39] - Despite such statements of successful urban freight plans, very few have been evaluated to explain why it is considered a success. Sharing experiences through evaluation would have meant many existing measures being improved and undesired measures avoided [77]. The UK transport plan process and impact evaluation emphasises that any evaluation should identify potential contextual changes and state whether the policy has met its original aims and objectives. It should identify what the plan has delivered and thereafter contribute to a second version [78-80]. For instance, Merseyside concluded that a greater emphasis was needed on the freight and logistics sector of the Local Transport Plan [39]. Several evaluations are planned: Västra Götaland will evaluate freight strategy through performance indicator sales, employment and $\mathrm{CO}_{2}$ emissions [31], and all completed actions in Stockholm will be followed up with measurement evaluations [16]. Useful recommendations on how to perform such evaluations may be found in the SUTP, SUMP, SULP methodologies [81].

\section{Conclusions}

A sustainable urban freight plan is a strategic plan with a detailed action plan or part of an urban mobility/city strategy. It is designed with a sustainability perspective on urban deliveries to define regional or local visions specified by selected policy measures and to satisfy the freight needs of people and business in the area. The urban freight plans identified have not yet fully embraced the concept of a Sustainable Urban Logistics Plan. However, sustainability is an important focus in the plans, with some country-specific differences in regard to emphasis on economic growth, environmental protection and social equity.

When developing urban freight plans, and like the SUTP, SUMP, SULP methodologies, a collaboration approach is practised in urban freight planning. Important considerations when developing freight plans are integrated transport planning and weighting of the regional perspectives against an urban/city perspective.

Governmental guidance is important in providing goals and a methodology for urban freight planning. In this paper it is found that national guidance is applied more often than European guidance, although the European methodologies are not without value. Both structural and organisational elements of the European SUTP, SUMP and SULP methodology are essential components of the existing Scandinavian and UK urban freight plans.

Steps towards increasing the development of these freight plans include incorporating freight-related issues in local transport planning together with walking and biking, and providing or improving national guidance for urban freight planning. Continued analysis of the success or failure of the urban freight plans and the identified policy measures are needed. By comparing multiple or evaluating one individual plan in more detail it will be possible to consider the impact of an urban freight plan, which so far has rarely been done.

Acknowledgements This work is undertaken as part of the research project NORSULP (Sustainable Urban Logistics Plans in Norway), financed by the Research Council of Norway and the Norwegian Public Roads Administration. Further information is available from www.norsulp.no (in Norwegian only).

Open Access This article is distributed under the terms of the Creative Commons Attribution 4.0 International License (http:// creativecommons.org/licenses/by/4.0/), which permits unrestricted use, distribution, and reproduction in any medium, provided you give appropriate credit to the original author(s) and the source, provide a link to the Creative Commons license, and indicate if changes were made.

\section{References}

1. European Commission (2013) A call to action on urban logistics. Commission Staff Working Document SWD (2013) 524 final

2. Lindholm M, Blinge M (2014) Assessing knowledge and awareness of the sustainable urban freight transport among Swedish local authority policy planners. Transp Policy 32:124-131

3. European Commission (2013) A concept for sustainable urban mobility plans, Annex to the Communication to the European Parliament, the Council, the European Economic and Social Committee of the Regions. COM 913 final

4. Ambrosino G (2014) Sustainable urban logistics plan (SULP): the experience of IEE ENCLOSE project in small and mid-sized European historic towns. Madrid, Spain

5. Gatta V, Marcucci E (2016) Stakeholder-specific data acquisition and urban freight policy evaluation: evidence, implications and new suggestions. Transp Rev 36(5):585-609

6. Lindholm M, Behrends S (2012) Challenges in urban freight transport planning - a review in the Baltic sea region. J Transp Geogr 22:129-136

7. Lindholm M (2010) A sustainable perspective on urban freight transport: factors affecting local authorities in the planning procedures. Proc Soc Behav Sci 2(3):6205-6216

8. Cherrett T, Allen J, McLeod F, Maynard S, Hickford M, Browne M (2012) Understanding urban freight activity - key issues for freight planning. J Transp Geogr 24:22-32

9. Quak H, Tavasszy L (2011) Customized solutions for sustainable city logistics: the viability of urban freight consolidation centres. In: van Nunen JAEE, Huijbregts P, Rietveld P (eds) Transitions towards sustainable mobility. Springer, Berlin Heidelberg, pp 213-233

10. Cui J, Dodson J, Hall PV (2015) Planning for urban freight transport: an overview. Transp Rev 35(5):583-598

11. Lindholm M, Behrends S (2010) A holistic approach to challenges in urban freight transport planning. 12th WCTR July 11-15 2010 Lisbon Portugal

12. Morfoulaki M, Mikiki F, Kotoula N, Myrovali G (2015) Integrating city logistics into urban mobility policies. 7th Int Congr Transp Res $1-14$ 
13. Oguztimur S, Canci M (2011) Urban logistics in master plan and a review on İstanbul master plan. European Regional Science Association, ERSA conference paper ersa $11 \mathrm{p} 830$

14. NORSULP (2016) Sustainable urban logistics plans in Norway. Institute of Transport Economics. https://www.toi.no/logistikkplaneri-by-norsulp/category 1667.html. Accessed 11 Oct 2016

15. ENCLOSE (2015) Guidelines. Developing and implementing a sustainable urban logistics plans. ENCLOSE

16. Stockholms stad (2014) The Stockholm Freight Plan 2014-2017: an initiative for safe, clean and effective freight deliveries. Stockhoms stad

17. Van Uytven A (2016) Sustainable Urban Transport Planning (SUTP). Eltis the urban mobility observatory. http://www.eltis. org/discover/case-studies/sustainable-urban-transport-planningsutp. Accessed 18 Sept 2016

18. European Communities (2007) Sustainable urban transport plans. Preparatory document in relation to the follow-up of the thematic strategy on the urban environment. Technical report 2007/018. European Communities, Luxembourg

19. Wefering F, Rupprecht S, Böhler-Baedeker S (2014) Guidelines. Developing and implementing a sustainable urban mobility plan. European platform on sustainable urban mobility plans

20. Lindholm M (2010) A sustainable perspective on urban freight transport: Factors affecting local authorities in the planning procedures. Proc Soc Behav Sci 2(3):6205-6216

21. Wolfram M (2004) Expert working group on sustainable urban transport plans. Rupprecht Consult, Cologne

22. European Commission (2013) A concept for sustainable urban mobility plans. Together towards competitive and resource-efficient urban mobility. European Commission, COM 913

23. Adell E, Ljungberg C (2014) The poly-SUMP methodology. How to develop a sustainable urban mobility plan for a polycentric region. European Platform on Sustainable Urban Mobility Plans

24. Petticrew M, Roberts H (2006) Systematic reviews in the social sciences: a practical guide. Blackwell Pub

25. Gough D, Oliver S, Thomas J (2013) Learning from research: systematic reviews for informing policy decisions - a quick guide

26. Uman LS (2011) Systematic reviews and meta-analyses. J Can Acad Child Adolesc Psychiatry 20(1):57-59

27. Ballantyne EEF, Lindholm M, Whiteing A (2013) A comparative study of urban freight transport planning: addressing stakeholder needs. J Transp Geogr 32:93-101

28. Harrison J, Hoyler M (2015) Megaregions: globalization's new urban form? Edward Elgar Pub, Cheltenham

29. Lindholm M (2012) Enabling sustainable development of urban freight from a local authority perspective. Dissertation, Chalmers University of Technology, Sweden, Gothenburg

30. Rodrigue J-P (2017) The geography of transport systems, Fourth edn. Routledge, New York

31. Västra Götalandsregionen (2016) Godstransportstrategi för Västra Götaland. Västra Götalandsregionen

32. Västra Götalandsregionen (2016) Godstransportstrategi för Västra Götaland. Handlingsplan. Västra Götalandsregionen

33. Northamptonshire County Council (2013) Northamptonshire road freight strategy. Northamptonshire County Council

34. Surrey County Council (2011) Surrey transport plan: freight strategy. Surrey County Council

35. Staffordshire City Council (2011) Staffordshire local transport plan 2011: Staffordshire freight strategy. Staffordshire City Council

36. Somerset County Council (2011) Transport policies - freight strategy. Somerset County Council

37. Kent County Council (2012) Freight action plan for Kent 20122016. Kent County Council

38. West Midlands Metropolitan County (2013) West Midlands Metropolitan Freight Strategy 2030. Supporting our Economy; Tackling Carbon. West Midlands Metropolitan County
39. Merseyside Local Transport Plan Support Unit (2011) The third local transport plan for merseyside. Freight strategy. Merseyside Local Transport Plan Support Unit

40. Transport for South Hampshire (2008) A freight strategy for urban south Hampshire. Transport for South Hampshire, South Hampshire

41. Transport for London (2007) London freight plan sustainable freight distribution: a plan for London. Transport for London, London

42. Transportministeriet (2011) Effektiv godstransport i byerne. Transportministeriet, Copenhagen

43. Bergen kommune (2003) Varedistribusjon i Bergen sentrum. Bergen kommune, Norway

44. Malmö stads: Gatukontoret (2013) Godstrafikprogram för Malmö 2014-2020. Malmö stads

45. Bedford Borough (2010) Bedford's freight strategy (2011-2021). Bedford Borough

46. West Berkshire Council (2014) West Berkshire Local Transport Plan. Freight Strategy. West Berkshire Council

47. Aberdeen City Council (2015) Aberdeen city centre sustainable urban mobility plan. AECOM Limited

48. Aberdeen City Council (2016) The Aberdeen city local transport strategy (LTS) 2016-2021. Aberdeen City Council, Aberdeen

49. Aberdeen City Council (2016) Sustainable urban mobility plan. Aberdeen City Council. http://www.aberdeencity.gov.uk/sump/. Accessed 03 Oct 2016

50. North East Scotland Freight Forum (2014) Nestrans Freight Action Plan 2014. North East Scotland Freight Forum

51. Dundee City Council (2014) Sustainable urban logistics plan for Dundee. Dundee City Council

52. Cave S, Rehfisch A, Smith L, Winter G (2013) Comparison of the planning system in the four UK countries. Inter-Parliamentary Research and Information Network (IPRIN), Northen Ireland, 082-13

53. Headicar P (2009) Transport policy and planning in Great Britain. Routledge

54. City of Stockholm Traffic Administration (2012) Stockholm urban mobility strategy. The City of Stockholm

55. Malmö stad (2016) Sustainable urban mobility plan. Creating a More Accessible Malmö. Malmö stad, Malmö

56. South East of Scotland Transport Partnership (2010) Freight Study \& Action Plan. South East of Scotland Transport Partnersh

57. Department for Communities and Local Government (2015) Plain English guide to the planning system. Department for Communities and Local Government, London

58. Lindholm M (2014) Färdplan Citylogistik - Godstransporter i urbana områden. Forum för innovation inom transportsektorn. CLOSER-report. CLOSER

59. Department for Transport (2007) Local authority freight management guide. Department for Transport, London

60. Department for Transport (2009) Guidance on local transport plans. Department for Transport, London

61. Department for Transport (2008) Delivering a sustainable transport system: the logistics perspective. Department for Transport, London

62. Department for Transport (2011) Creating growth, cutting carbon. Making sustainable local transport happen - White Paper. Department for Transport, London

63. Scottish Government (2014) Transport noise action plan. Environmental Noise Directive, Scotland

64. Department for Communities and Local Government (2012) National planning policy framework. Department for Communities and Local Government, London

65. Tayside and Central Scotland Transport Partnership (2008) TACTRAN Regional Transport Strategy 2008-2012. Tayside and Central Scotland Transport Partnership, Angus, Dundee City, Perth and Kinross, Stirling

66. Central Bedfordshire Council (2009) Core strategy and development management policies. Central Bedfordshire Council, Central Bedfordshire 
67. Dalton RJ (2014) Citizen politics: public opinion and political parties in advanced industrial democracies, 6th edn. CQ Press Sage Publications Inc., Los Angeles

68. National Cooperative Freight Research Program (2015) Improving freight system performance in metropolitan areas: a planning guide. USA, Washington

69. Brundtland GH (1987) Our common future: the world commission on environment and development. Oxford University Press, Oxford

70. Behrends S, Lindholm M, Woxenius J (2008) The impact of urban freight transport: a definition of sustainability from an actor's perspective. Transp Plan Technol 31(6):693-713

71. Department for Transport (2008) Delivering a sustainable transport system: main report. Department for Transport, London

72. Browne M, Allen J, Attassy M (2007) Comparing freight transport strategies and measures in London and Paris. Int J Logist 10(3):205-219

73. Stathopoulos A, Valeri E, Marcucci E (2012) Stakeholder reactions to urban freight policy innovation. J Transp Geogr 22:34-45

74. Lindenau M, Böhler-Baedeker S (2014) Citizen and stakeholder involvement: a precondition for sustainable urban mobility. Transp Res Proc 4:347-360
75. May AD, Kelly C, Shepherd S (2006) The principles of integration in urban transport strategies. Transp Policy 13(4):319-327

76. Browne M, Allen J, Nemoto T, Patier D, Visser J (2012) Reducing social and environmental impacts of urban freight transport: a review of some major cities. Proc Soc Behav Sci 39:19-33

77. Quak H (2011) Urban freight transport: the challenge of sustainability. Edward Elgar Publishing, Chapters

78. Great Minster House Department for Transport (2004) Long term process and impact evaluation of DfT's local transport plans policy. Department for Transport, London

79. Department for Transport (2005) Long term process and impact evaluation of the local transport plan policy. Department for Transport, London

80. Department for Transport (2007) Review of future options for local transport planning in England. Department for Transport

81. CH4LLENGE (2016) Monitoring and evaluation. Assessing the impact of measures and evaluation mobility planning processes. European Platform on Sustainable Urban Mobility Plans 